\title{
Coincidence of Congenital Diaphragmatic Hernia and Arnold Chiari II Malformation: A Case Report
}

\author{
Paudel $\mathbf{S}^{1}$, Kayastha $\mathbf{P}^{1}$, Pradhan $\mathbf{R}^{2}$, Ghimire RK ${ }^{1}$, Ansari MA ${ }^{1}$
}

${ }^{1}$ Department of Radiology and Imaging, Institute of Medicine, Tribhuvan University Teaching Hospital, Kathmandu, Nepal, ${ }^{2}$ Siddhi CT Scan Pvt. Ltd, Kathmandu, Nepal

\begin{abstract}
Congenital diaphragmatic hernia is the developmental abnormality in which abdominal viscera herniate into the thoracic cavity through defect in the diaphragm. Almost $10 \%$ of congenital diaphragmatic hernia has associated central nervous system malformation including anencephaly, myelomeningocele and hydrocephalus. The Arnold-Chiari malformation is a congenital abnormality of Central Nervous System (CNS), characterized by downward displacement of the parts of the cerebellum, fourth ventricle, pons and medulla oblongata into the spinal canal. Here we present an extremely rare case with coexistent congenital diaphragmatic hernia and Arnold Chiari II malformation occurring in a viable fetus of 20 weeks gestational age.
\end{abstract}

Keywords: Arnold Chiari II malformation, Congenital diaphragmatic hernia, Ultrasonography

\section{Introduction}

The incidence of congenital diaphragmatic hernia $(\mathrm{CDH})$ has been reported as 1 in 30005000 live births. ${ }^{1}$ Herniation of abdominal contents occurs most often, in over $95 \%$ of cases, through the posterior foramen of Bochdalek, posterior and lateral to the spine, with $80 \%$ occurring on the left side. ${ }^{2}$ Less commonly, retrosternal herniation occurs, through the foramen of Morgagni or herniation occurs through esophageal hiatus. $\mathrm{CDH}$ may be an isolated anomaly or it may be associated with various syndromes. CNS

Correspondence to: Dr. Sharma Paudel, Department of Radiology and Imaging, Institute of Medicine, Tribhuvan University Teaching Hospital, Kathmandu, Nepal E-mail:sharmapaudel@hotmail.com. anomalies coexist in up to $10 \%$ of nonsyndromic $\mathrm{CDH}$ cases; the most common diagnoses are neural tube defects and hydrocephalus. ${ }^{3}$ The reason for the association with a neural tube defect is not known, but has been postulated to be a problem of schisis-fusion or midline instability.

Arnold-Chiari malformation with an incidence of 0.4:1000 live-birth is one of the CNS abnormalities that has formed $3 \%$ of all abortion and 1-2\% recurrent risk. ${ }^{4}$ Among three Arnold- Chiari malformations, type II is the most common and is characterized by displacement of cerebellar tonsils, fourth ventricle, pons and medulla oblongata through the foramen magnum into the spinal canal. This is usually associated with hydrocephalus and myelomeningocele. The obvious sonographic findings in antenatal ultrasound 
are the frontal bone scalloping (lemon sign) and effaced cisterna magna with abnormal anterior curvature of the cerebellar hemispheres (banana sign).

We report one case of congenital diaphragmatic hernia associated with Arnold Chiari II malformation detected at 20 weeks routine antenatal ultrasonography. This is probably the first case report of coexistent congenital diaphragmatic hernia with Arnold Chiari II malformation as no pubmed search result was obtained on such case report.

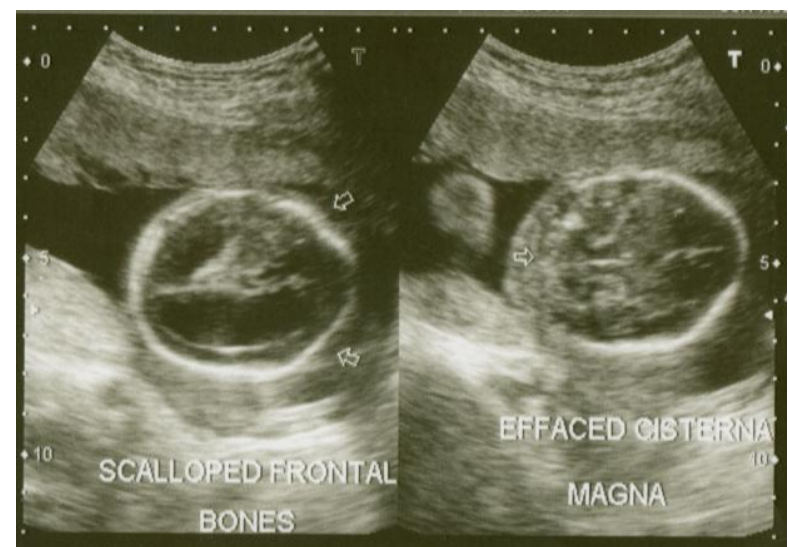

Fig 1 a: Dilated lateral ventricles and scalloping of frontal bones "Lemon sign" (arrows), b: Effaced cisterna magna with stretched cerebellum "Banana sign".

\section{Case Report}

A 28 year old primigravida was referred for routine anomaly scan at 20 weeks of gestation. She didn't have any risk factors. Average gestational age calculated with ultrasonography was 19 weeks and 4 days. On routine ultrasonography we found dilated bilateral lateral ventricles [Fig 1a]. Posterior fossa was small with effaced cistern magna and compressed and stretched cerebellum giving "banana sign" [Fig: 1b]. There was scalloping of bilateral frontal bones "lemon sign" [Fig: 1a]. Dysrrhaphic spine was seen in lumbar region with a cystic swelling containing multiple linear septations protruding posteriorly representing myelomeningocele [Fig: 2]. The fetus also had right club foot. Scanning at the level of fetal abdomen we didn't find stomach in its normal position. On further searching, it was located in the posterior aspect of left thoracic cavity with displacement and compression of heart towards right and normal hypoechoic diaphragm was not visualized [Fig: 3]. These features were suggestive of left sided congenital diaphragmatic hernia, the most common Bodachlek's type. Amniotic fluid was within normal limits. No other structural abnormalities were detected. These all the findings were confirmed by four other radiologists with 3-15 years of experience in obstetric ultrasound. Unfortunately patient was lost from our follow up and we could not evaluate for any syndromic association, chromosomal anomalies or confirm our findings postnatally.

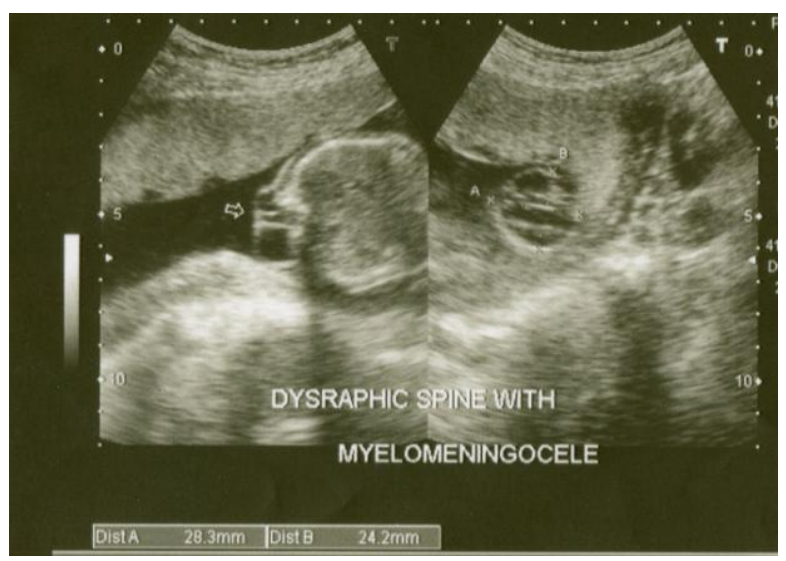

Fig 2: Cystic swelling with septations in the posterior aspect of lumbar region (myelomeningocele).

\section{Discussion}

The 3 basic types of congenital diaphragmatic hernia include the postero- lateral Bochdalek hernia, the anterior Morgagni hernia, and the hiatus hernia. The left-sided Bochdalek hernia occurs in approximately $80-85 \%$ of cases. Left-sided hernias allow herniation of stomach, both the small and large bowel and intraabdominal solid organs into the thoracic 
cavity. In right-sided hernias, only the liver and a portion of the large bowel tend to herniate. Bilateral hernias are uncommon and are usually fatal.

Despite advances in antenatal detection, perinatal mortality remains high. Prenatal ultrasound detection is only successful in 50\% of cases, ${ }^{3,5}$ with regional variation from $29 \%$ to $100 \%$. This increases to $72 \%$ if additional anomalies or an abnormal karyotype are detected. ${ }^{5}$ A significant number are detected after 24 weeks of gestation. $\mathrm{CDH}$ is most commonly diagnosed on ultrasound by the presence of abdominal organs within the thoracic cavity. Indirect signs include polyhydramnios, abnormal cardiac axis and mediastinal shift. Right sided $\mathrm{CDH}$ may be especially difficult to detect, as the liver has similar echogenicity to the lung, and may be the only organ to have herniated into the chest. Localization of the gallbladder and other indirect signs may be especially useful in this case.

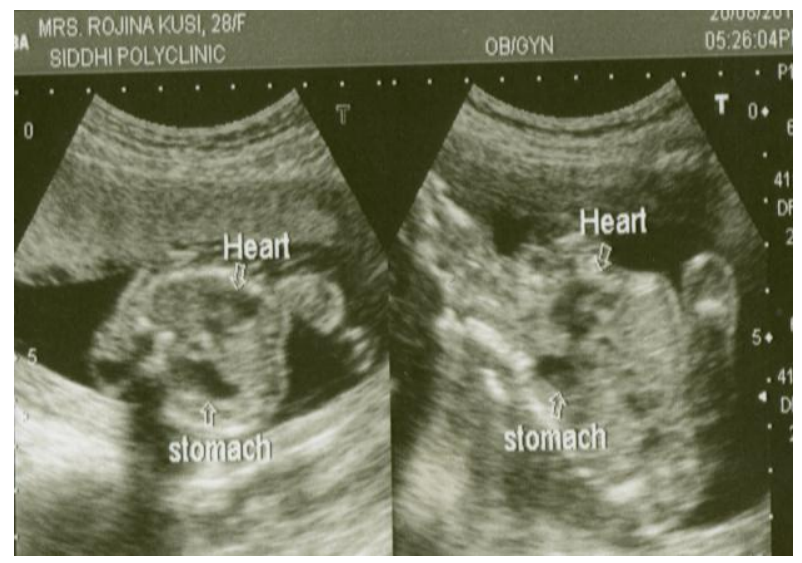

Fig 3: Axial and sagittal sonographic images showing stomach in the thoracic cavity posterior and left to the heart which is compressed towards right.

Associated structural anomalies are found in $39 \%$ of cases (ranging from $25 \%$ to $58 \%$ in reported series), ${ }^{6}$ Most common are congenital heart defects (patent ductus arteriosus, ventricular septal defects, tetralogy of Fallot, or cardiac hypoplasia), renal (23\%), central nervous system (10\%), and gastrointestinal (GI) anomalies $(14 \%){ }^{7}$ In cases of fetal demise, central nervous system defects predominate.

Isolated $\mathrm{CDH}$ is a sporadic condition, with familial cases accounting for less than $2 \% .^{8}$ Familial cases are more likely to be isolated findings and have a higher incidence of bilateral defects.

CDH may also occur as part of a syndrome, with at least $10 \%$ of patients with $\mathrm{CDH}$ and additional birth defects estimated to have an underlying syndromal diagnosis. ${ }^{9}$ Various syndromes described include Fryns syndrome, Beckwith-Wiedemann syndrome, Brachmande Lange syndrome, Simpson-Golabi-Behmel syndrome, Donnai syndrome etc. The underlying mechanism of pathogenesis of $\mathrm{CDH}$ in these syndromes remains unclear.

Chromosomal defects occur in $33 \%$ of cases with $\mathrm{CDH},{ }^{9}$ with multiple anomalies more likely to have chromosomal abnormalities. Turners syndrome and trisomy 21 are the most commonly reported. ${ }^{10}$

Perinatal outcome, broadly speaking, depends on a number of core factors: the presence of additional anomalies, the gestational stage at herniation, the volume of intra-thoracic organs; and extent of resultant lung hypoplasia and cardiovascular changes.

Multiple studies have evaluated the accuracy of sonography for diagnosis of Chiari malformation. ${ }^{10-12}$ The feature of the Chiari II malformation that have been most useful are the infratentorial findings, these include effacement of the cisterna magna ${ }^{10}$ and deformation of the cerebellum which is called banana sign, although other infratentorial abnormalities are commonly observed postnatally. ${ }^{11,12}$ Although the dominant feature of chiari malformation relate to the hindbrain, 
many supratentorial abnormalities have also been described. ${ }^{11,12}$ Included in these are callosal dysgenesis, enlarged interthalamic adhesion, a beaked tectum, polymicrogyria, heterotopias, skull deformities (the "lemon sign"), colpocephaly, and other cause of vertriculomegaly. Important among these is vertriculomegaly. Unfortunately, ventriculomegaly is considerably less common before 24 weeks than after 24 weeks in fetuses affected with myelomeningocele. The cranial findings associated with the Chiari II malformation are found exclusively in fetuses with myelomeningocele. Therefore, identification of features of the Chiari II malformation virtually ensures that myelimeningocele is present.

Our case had left sided Bochdalek type of congenital diaphragmatic hernia associated with features of Chiari II malformation. The reason for the association of $\mathrm{CDH}$ with a neural tube defect is not known, but has been postulated to be a problem of schisis-fusion or midline instability.

\section{Conclusion}

Coexistence of congenital diaphragmatic hernia and Chiari II malformation is extremely rare and was detected in antenatal ultrasonography. Antenatal detection of these abnormalities are important for counseling, prognostication, antenatal therapy and postnatal management.

\section{References}

1. Butler N, Claireaux AE. Congenital diaphragmatic hernia as a cause of perinatal mortality.Lancet1962;1:659-663.

2. Lally KP.Congenital diaphragmatic hernia. Curr Opin Pediatr 2002;14:486-490.

3. Dillon E, Renwick M, Wright C. Congenital diaphragmatic herniation: antenatal detection and outcome. $\mathrm{Br} \mathrm{J}$ Radiol. 2000;73:360-5.
4. Woodward P, Kennedy A, Sohaey R, Byrne JLB, Oh KY, Puchalski MD. Diagnostic imaging. 1sted. Canada, Amirsys Elsevier Saunders. 2005; chapter 2:21.

5. Garne E, Haeusler M, Barisic I, Gjergja R, Stoll C, Clementi M. Congenital diaphragmatic hernia: evaluation of prenatal diagnosis in 20 European regions. Ultrasound Obstet Gynecol 2002;19: 329-333.

6. Skari H, Bjornland K, Haugen G, Egeland T, Emblem R. Congenital diaphragmatic hernia: a meta-analysis of mortality factors.J Pediatr Surg 2000;35:1187-1197.

7. Skarsgard ED, Harrison MR. Congenital diaphragmatic hernia: the surgeon's perspective. Pediatr Rev 1999;20:e71-e78.

8. Tibboel D, Gaag AV. Etiologic and genetic factors in congenital diaphragmatic hernia. Clin Perinatol 1996; 23: 689-699.

9. Enns GM, Cox VA, Goldstein RB, Gibbs DL, Harrison MR, Golabi M. Congenital diaphragmatic defects and associated syndromes, malformations, and chromosome anomalies: a retrospective study of 60 patients and literature review. Am J Med Genet 1998;79:215-225.

10. Goldstein RB, Podrasky AE, Filly RA, Callen PW. Effacement of the fetal cisterna magna in association with myelomeningocele. Radiology. 1989; 172(2):409-413.

11. McLone DG, Dias MS. The Chiari II malformation: cause and impact Childs Nerv Syst. 2003; 19(7-8): 540-550.

12. Barkovich JA. Congenital malformarmation of the brain and skull. In: Barkovich JA(ed). Pediatric Neuroimaging. 4th ed. Philadelphia, PA: Lippincott Williams \& Wilkins; 2005: 378-384 